\title{
EXAMINATION OF THE APPLICATION POSSIBILITIES OF WASTE RED MUD IN TREATMENT OF COLORED EFFLUENT
}

\author{
Aleksandra Kulić ${ }^{1}$ (D), Milena Bečelić-Tomin ${ }^{1}$ (D), Đurđa Kerkez ${ }^{1}$ (D), \\ Gordana Pucar Milidrag ${ }^{1}$ (D), Vesna Kecić ${ }^{2}$ (D), Miljana Prica ${ }^{2}$ \\ ${ }^{1}$ University of Novi Sad, Faculty of Sciences, Department of Chemistry, \\ Biochemistry and Environmental Protection, Novi Sad, Serbia \\ ${ }^{2}$ University of Novi Sad, Faculty of Technical Sciences, \\ Department of Graphic Engineering and Design, Novi Sad, Serbia
}

\begin{abstract}
The most important component of coloured wastewaters is the synthetic dyes, which cause negative effects on aquatic ecosystems due to great solubility and persistence. Previous research points out that the heterogeneous Fenton process can be applied as an effective treatment of this type of wastewater. In this paper, the possibility of using waste red mud (RM), as a catalyst for the Fenton reaction, has been investigated. Sample of wastewater was obtained from the local textile industry, as follows: effluent before and after biological treatment. The optimization process was carried out using the response surface methodology, where the $\mathrm{pH}$ value, the concentration of $\mathrm{H}_{2} \mathrm{O}_{2}$ and the catalyst dose was varied. The following optimal reaction conditions were obtained for raw effluent: $p H=3.26 ;\left[\mathrm{H}_{2} \mathrm{O}_{2}\right]=10 \mathrm{mM}$; $[R M]=0.09 \mathrm{~g}$, while for effluent after biological treatment: $p H=3 ;\left[\mathrm{H}_{2} \mathrm{O}_{2}\right]=4.28 \mathrm{mM} ;[R M]=0.1 \mathrm{~g}$. Under the given conditions, the efficiency of the Fenton process was 61.83 and $79.65 \%$, respectively.
\end{abstract}

Key words: Fenton, red mud, RSM, CCD, effluent

\section{INTRODUCTION}

Large quantities of discharged coloured wastewaters from textile mills are characterized by high chemical oxygen demand, suspended solids, heavy metals, salts, etc. The use of multiple technological processes (dyeing, finishing, sizing, washing, rinsing) contributes to the highly variable nature of textile effluents (Babuponnusami \& Muthukumar, 2014; Soltani \& Safari, 2016).

Biological treatment processes are widely used because they are economical, but after all not able to efficiently degrade present synthetic dye molecules in the wastewaters. So, advanced oxidation processes (AOPs) can be used in order to mineralise dyes in textile effluents (Benatti \& Tavares, 2008). Among them, Fenton process is known as a reaction between hydrogen-peroxide (oxidant) and iron species (catalyst) to generate highly reactive hydroxyl radicals ( $\mathrm{HO}^{\circ}$ ) that can efficiently degrade dye molecules (Bezerra et al, 2008; Davarnejad \& Azizi, 2016; Gebrati et al, 2018). The wide range of materials can be used as catalysts in heterogeneous Fenton processes, where even industrial solid wastes can find its purpose (Gebrati et al, 2018). One of them is red mud (RM) from alumina factory that could be used, because it is consisted of iron minerals among others constituents. Nowadays researches are oriented towards combining these processes for achieving a satisfactory level of coloured effluent purification (Benatti \& Tavares, 2008). Also, evaluation of optimal experimental conditions must be conducted, where response surface methodology (RSM) can be used as a tool. The main types of RSM designs are full factorial design, central composite design (CCD), Box-Behnken design and D-optimal design (Lodha \& Chaudhari, 2007).

In this study, $\mathrm{CCD}$ was used to optimize heterogeneous Fenton process parameters ( $\mathrm{pH}$ value, initial $\mathrm{H}_{2} \mathrm{O}_{2}$ concentration and catalyst dose) for obtaining satisfactory decolourization of raw textile effluent and effluent after biological treatment. Moreover, as a catalyst in Fenton reaction was used RM after thermal modification at $550^{\circ} \mathrm{C}$.

\section{METHODS}

\subsection{Materials}

Commercially purchased chemicals, $30 \% \mathrm{H}_{2} \mathrm{O}_{2}, \mathrm{H}_{2} \mathrm{SO}_{4}$ and bovine liver catalase, were used in this work without any further purification (Sigma-Aldrich Company). Waste RM collected from the alumina factory (Bosnia and Herzegovina) was used as catalyst in the heterogeneous Fenton process after thermal modification (RM-550). The main steps of catalyst preparation are shown in the figure 1. Coloured 
effluents from local textile mill (Serbia) were collected before and after biological treatment, named as rawEF and afterBT, respectively. Table 1 shows characterization of these wastewaters.

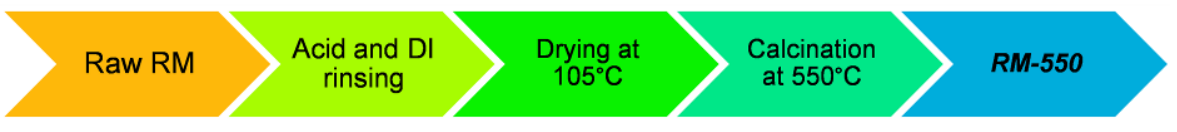

Figure 1: Steps of thermal modification of RM

Table 1: Main characteristics of coloured effluents

\begin{tabular}{ccccccc}
\hline Parameter & $\mathrm{COD}\left(\mathrm{mgO}_{2} / \mathrm{l}\right)$ & $\mathrm{BOD}\left(\mathrm{mgO}_{2} / \mathrm{l}\right)$ & Total $\mathrm{N}(\mathrm{mgN} / \mathrm{l})$ & Total $\mathrm{P}(\mathrm{mgP} / \mathrm{l})$ & $\mathrm{pH}$ value & Color \\
\hline Effluent & 627 & 360 & 16 & 0.1 & 6.9 & Dark purple \\
rawEF & 497 & 127 & 12 & 2.6 & 7.7 & Black \\
\hline
\end{tabular}

\subsection{Heterogeneous Fenton process}

Decolourization of textile effluents were conducted as follows: convenient amount of RM-550 was added to $100 \mathrm{ml}$ of real sample, after what $\mathrm{pH}$ value was set with diluted $\mathrm{H}_{2} \mathrm{SO}_{4}$. Next, initial concentration of $\mathrm{H}_{2} \mathrm{O}_{2}$ was added and mixing of this mixture was set at $120 \mathrm{rpm}$ at JAR test apparatus during a predetermined time. For termination of Fenton reaction $1 \mathrm{ml}$ of catalase solution $(0.1 \mathrm{~g} / \mathrm{l})$ was added to the mixture. The catalyst was separated by centrifugation (Sigma 3-30K) for 5 minutes at $10000 \mathrm{rpm}$. Evaluation of treatment efficacy was executed by measuring absorbance at UV/VIS spectrophotometer (UV 1800, Shimadzu, Japan), $\lambda_{\max }(\operatorname{rawEF})=579.5 \mathrm{~nm}$ and $\lambda_{\max }(\operatorname{afterBT})=592 \mathrm{~nm}$. Percent of dye degradation was calculated according to the formula (1).

$\frac{A_{O}-A}{A_{O}} \cdot 100=$ Decolourization $(\%)$

Where Ao was initial absorbance value for effluent, and A value was sample absorbance after specified reaction condition and time.

\subsection{Experiment design}

Effect of three independent variables (A-pH value, B-initial concentration of $\mathrm{H}_{2} \mathrm{O}_{2}$ and C-dosage of RM-550) on response-decolourization efficacy, were investigated employing CCD experimental design and RSM by the software Design-Expert 7.0.0. (Stat-Ease Inc., Minneapolis, USA). The actual values of coded maximum, central and minimum levels $(-2,-1,0,+1,+2)$ for each variable are given in table 2 .

Table 2: Coded and actual values for experimental parameters

\begin{tabular}{cccccccc}
\hline \multirow{2}{*}{ Symbol } & Parameter & Unit of & \multicolumn{4}{c}{ Range of independent variables } \\
\cline { 5 - 8 } & & measure & -2 & -1 & 0 & +1 & +2 \\
\hline $\mathrm{A}$ & $\mathrm{pH}$ value & - & 1.98 & 3.00 & 4.50 & 6.00 & 7.02 \\
$\mathrm{~B}$ & Initial concentration of $\mathrm{H}_{2} \mathrm{O}_{2}$ & $\mathrm{mM}$ & 0.61 & 3.00 & 6.50 & 10.0 & 12.4 \\
$\mathrm{C}$ & Initial dosage of $\mathrm{RM}-550$ & $\mathrm{~g}$ & 0.03 & 0.05 & 0.08 & 0.10 & 0.12 \\
\hline
\end{tabular}

\section{RESULTS}

According to the CCD 20 experimental probes were designed, where probes 1-8 presents full factorial design, 9-14 star design and 15-20 central point repetitions. The order of runs, the real values of factors, the actual experimental and predicted values for the decolourization efficiency of both effluents, rawEF and afterBT, are given in Table 3. The actual values of the response vary between 1.02 to $69.1 \%$ and 2.79 to $92.5 \%$, respectively. For both effluents the relation between the independent variables and observed response was described by a second order polynomial model and the experimental data were fitted by square function. Also, ANOVA test was implemented and significant interactions between variables such as $\mathrm{pH}$ and initial $\mathrm{H}_{2} \mathrm{O}_{2}$ concentration $(A B), \mathrm{pH}$ and $\mathrm{RM}-550$ dose $(A C)$, initial $\mathrm{H}_{2} \mathrm{O}_{2}$ 
concentration and RM-550 dose $(B C)$, as well as $\left(A^{2}\right),\left(B^{2}\right),\left(C^{2}\right)$ are presented in table 4 . Further, these interactions are also presented as 3D graphs in the figure 2 and 3.

Table 3: The matrix of the experimental design, with actual and predicted values for dependent variables

\begin{tabular}{ccccccccc}
\hline Std Order & \multicolumn{3}{c}{ Run Order } & \multicolumn{3}{c}{ Parameter } & \multicolumn{3}{c}{ Decolourization efficiency (\%) } \\
& & $\mathrm{pH}$ & $\mathrm{c}\left(\mathrm{H}_{2} \mathrm{O}_{2}\right)$ & $\mathrm{m}(\mathrm{RM}-550)$ & Actual & Predicted & Actual & Predicted \\
\hline 1 & 18 & 3.00 & 3.00 & 0.05 & 39.9 & 45.1 & 58.8 & 57.0 \\
2 & 1 & 6.00 & 3.00 & 0.05 & 1.02 & 16.5 & 6.44 & 12.3 \\
3 & 15 & 3.00 & 10.0 & 0.05 & 38.5 & 46.0 & 64.6 & 71.4 \\
4 & 16 & 6.00 & 10.0 & 0.05 & 7.34 & 13.1 & 15.5 & 16.1 \\
5 & 10 & 3.00 & 3.00 & 0.10 & 54.6 & 61.8 & 77.0 & 86.2 \\
6 & 9 & 6.00 & 3.00 & 0.10 & 23.6 & 29.1 & 41.9 & 44.8 \\
7 & 8 & 3.00 & 10.0 & 0.10 & 69.1 & 66.6 & 75.5 & 79.4 \\
8 & 14 & 6.00 & 10.0 & 0.10 & 21.8 & 29.6 & 15.9 & 27.5 \\
9 & 7 & 1.98 & 6.50 & 0.08 & 57.6 & 53.5 & 82.2 & 76.2 \\
10 & 19 & 7.02 & 6.50 & 0.08 & 12.6 & -1.62 & 2.79 & -5.05 \\
11 & 20 & 4.50 & 0.61 & 0.08 & 67.5 & 53.8 & 56.2 & 51.3 \\
12 & 4 & 4.50 & 12.4 & 0.08 & 59.8 & 55.0 & 57.7 & 48.8 \\
13 & 17 & 4.50 & 6.50 & 0.03 & 38.2 & 24.3 & 48.9 & 46.8 \\
14 & 3 & 4.50 & 6.50 & 0.12 & 56.7 & 52.2 & 92.5 & 80.8 \\
15 & 5 & 4.50 & 6.50 & 0.08 & 50.7 & 57.2 & 39.7 & 57.6 \\
16 & 11 & 4.50 & 6.50 & 0.08 & 58.9 & 57.2 & 69.5 & 57.6 \\
17 & 2 & 4.50 & 6.50 & 0.08 & 56.5 & 57.2 & 53.4 & 57.6 \\
18 & 12 & 4.50 & 6.50 & 0.08 & 57.2 & 57.2 & 57.7 & 57.6 \\
19 & 6 & 4.50 & 6.50 & 0.08 & 60.4 & 57.2 & 71.8 & 57.6 \\
20 & 13 & 4.50 & 6.50 & 0.08 & 56.5 & 57.2 & 51.1 & 57.6 \\
\hline
\end{tabular}

Table 4: ANOVA test results for quadratic model

\begin{tabular}{|c|c|c|c|c|c|c|c|c|c|c|}
\hline Source & Model & $A$ & $B$ & $C$ & $A B$ & $A C$ & $\mathrm{BC}$ & $A^{2}$ & $\mathrm{~B}^{2}$ & $C^{2}$ \\
\hline \multicolumn{11}{|c|}{ rawEF } \\
\hline $\begin{array}{l}\text { Sum of } \\
\text { squares }\end{array}$ & 6865.6 & 3670.2 & 1.67 & 943.9 & 9.34 & 8.55 & 7.80 & 1761.4 & 14.0 & 647.3 \\
\hline df & 9 & 1 & 1 & 1 & 1 & 1 & 1 & 1 & 1 & 1 \\
\hline $\begin{array}{l}\text { Mean } \\
\text { square }\end{array}$ & 762.9 & 3670.2 & 1.67 & 943.9 & 9.34 & 8.55 & 7.80 & 1761.4 & 14.0 & 647.3 \\
\hline$F$ value & 6.33 & 30.5 & 0.01 & 7.83 & 0.08 & 0.07 & 0.06 & 14.62 & 0.12 & 5.37 \\
\hline$P$ value & 0.0040 & 0.0003 & 0.9086 & 0.0188 & 0.7864 & 0.7953 & 0.8043 & 0.0034 & 0.7406 & 0.0429 \\
\hline \multicolumn{11}{|c|}{ afterBT } \\
\hline $\begin{array}{l}\text { Sum of } \\
\text { squares }\end{array}$ & 10730.6 & 7968.5 & 7.52 & 1400.2 & 56.4 & 5.53 & 223.4 & 872.7 & 102.0 & 69.4 \\
\hline df & 9 & 1 & 1 & 1 & 1 & 1 & 1 & 1 & 1 & 1 \\
\hline $\begin{array}{l}\text { Mean } \\
\text { square }\end{array}$ & 1192.3 & 7968.5 & 7.52 & 1400.2 & 56.4 & 5.53 & 223.4 & 872.7 & 102.0 & 69.4 \\
\hline F value & 8.59 & 57.4 & 0.05 & 10.1 & 0.41 & 0.04 & 1.61 & 6.29 & 0.73 & 0.50 \\
\hline$P$ value & 0.0012 & $<0.0001$ & 0.8206 & 0.0099 & 0.5381 & 0.8458 & 0.2334 & 0.0311 & 0.4114 & 0.4956 \\
\hline
\end{tabular}

\section{DISCUSSION}

Determination of statistically significant independent variables was conducted through Fisher's test (table 3) (Lodha \& Chaudhari, 2007; Soltani \& Safari, 2016). 6.33 and 8.59 were F-values for quadratic model, for both effluents respectively, which implies the statistical importance of the model. Further, $p$-values $<0.05$ point out which model terms are significant and $p$-values $>0.1$ indicate which model terms are not significant. Based on this explanation terms of importance are $A, C, A^{2}$ and $C^{2}$ for decolourization efficacy of coloured textile effluents. The coefficients of determination $\left(R^{2}\right)$ for process efficiency were 0.8507 and 0.8854 , for rawEF and afterBT effluent, respectively. Thus indicating that the applied model was statistically significant and modelled responses fit well with experimental data. 
Three-dimensional surface plots were applied to represent the interaction between the examined parameters. According to the table 3 and ANOVA test, the $\mathrm{pH}$ value is one of the significant parameters which affect heterogeneous Fenton process efficiency, thus controlling the catalytic activity of RM-550 and $\mathrm{H}_{2} \mathrm{O}_{2}$ stability. Interaction between $\mathrm{pH}$ and initial $\mathrm{H}_{2} \mathrm{O}_{2}$ concentration was examined at constant $\mathrm{RM}-550$ dose $\left(0.08 \mathrm{~g}\right.$ ) (fig. $2 \mathrm{a}, 3 \mathrm{a}$ ). Even when changing the entire $\mathrm{H}_{2} \mathrm{O}_{2}$ concentration range, a low $\mathrm{pH}$ is responsible for a high decolourization percentage, which is in accordance with the literature data where is stated that Fenton process is most effective in the narrower $\mathrm{pH}$ range (2-4). Lower efficacy can be explained due to $\mathrm{H}_{2} \mathrm{O}_{2}$ instability at higher $\mathrm{pH}$ values, where it starts to break down on molecular oxygen without forming a sufficient amount of $\mathrm{HO}^{\bullet}$ (Torrades \& Garcia-Montano, 2014; Nidheesh, 2015)). Interaction between $\mathrm{pH}$ and $\mathrm{RM}-550$ dosage was examined at constant $\mathrm{H}_{2} \mathrm{O}_{2}$ concentration (6.50 mM) (fig. 2b, 3b). A noticeable trend of growth of heterogeneous Fenton process efficiency can be seen with lowering pH values and increasing RM-550 dose. According to the literature data (Bezerra et al., 2008; Soltani \& Safari, 2016)) catalyst dosage is in direct proportion to a Fenton process efficacy, because with its increase there is a larger amount of available active sites, which produce $\mathrm{HO}^{\circ}$ and therefore the organic pollutant degradation increases. Highest process efficiency was achieved at pH 3.00 and $0.10 \mathrm{~g}$ for rawEF (69.1\%) and at $\mathrm{pH} 4.50$ and $0.12 \mathrm{~g}$ for effluent afterBT (92.5\%), thus confirming the previous statement. There is also a possibility of dye molecule adsorption to occur on the surface of RM-550, and therefore increasing discoloration of coloured effluents. Interaction between RM-550 dosage and initial $\mathrm{H}_{2} \mathrm{O}_{2}$ concentration was examined at constant $\mathrm{pH}$ (4.50) (fig. 2c, 3c). It is evident that $\mathrm{H}_{2} \mathrm{O}_{2}$ concentration has only slight effect on decolourization of rawEF, in contrast to the catalyst dose. On the other hand, highest dye removal is achieved with lower $\mathrm{H}_{2} \mathrm{O}_{2}$ concentration and highest RM-550 dosage, where with increasing of oxidant concentration Fenton process efficiency is decreasing. This trend could be associated with sufficient production of $\mathrm{HO}^{*}$ from $\mathrm{H}_{2} \mathrm{O}_{2}$ on the surface of the catalyst, and therefore providing rise of both effluents colour removal (Nidheesh, 2015; Davarnejad \& Azizi, 2016; Soltani \& Safari, 2016).

The desired goal of the model is to maximize decolourization efficiency to achieve highest treatment performance. The optimum values of the independent variables are shown in table 5 for both observed effluents. After verification through a further experimental test the result indicates that the efficiency was in good correlation with the predicted values. Achieved decolourization was $61.8 \%$ and $79.7 \%$ for rawEF and afterBT, respectively, which can be due to the low content of present heavily biodegradable organic matter and dyes.

a)

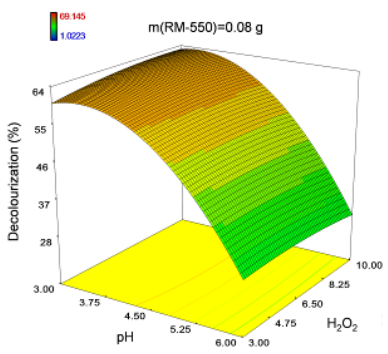

b)

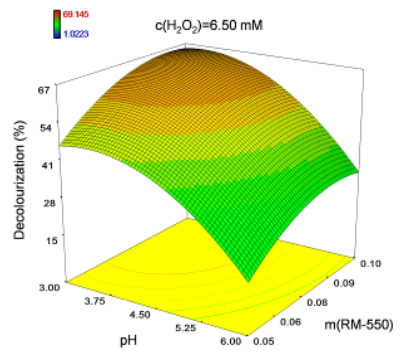

c)

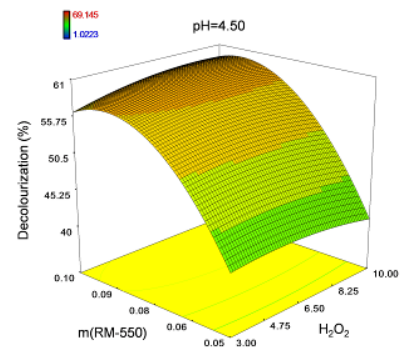

Figure 2: The effect of $\mathrm{pH}$ value, initial $\mathrm{H}_{2} \mathrm{O}_{2}$ concentration and $\mathrm{RM}-550$ dosage on the decolourization efficiency of effluent rawEF

a)

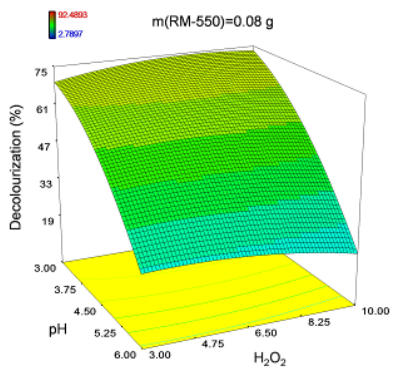

b)

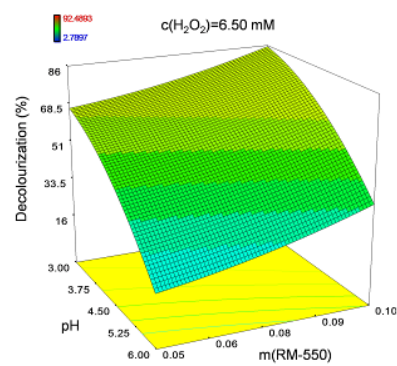

c)

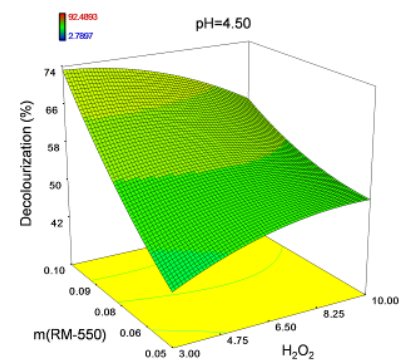

Figure 3: The effect of $\mathrm{pH}$ value, initial $\mathrm{H}_{2} \mathrm{O}_{2}$ concentration and $\mathrm{RM}-550$ dosage on the decolourization efficiency of effluent afterBT 
Table 5: Optimal values for the independent variables and heterogeneous Fenton process efficiency

\begin{tabular}{cccccc}
\hline $\begin{array}{c}\text { Coloured } \\
\text { effluent }\end{array}$ & $\mathrm{pH}$ & $\mathrm{c}\left(\mathrm{H}_{2} \mathrm{O}_{2}\right)$ & $\mathrm{m}(\mathrm{RM}-550)$ & \multicolumn{2}{c}{ Decolourization efficiency (\%) } \\
Actual & Predicted \\
\hline rawEF & 3.26 & 10 & 0.09 & 61.8 & 67.3 \\
afetrBT & 3.00 & 4.3 & 0.10 & 79.7 & 86.5 \\
\hline
\end{tabular}

\section{CONCLUSIONS}

The aim of this paper was investigating the possibility of thermally treated waste red mud as a catalyst in the heterogeneous Fenton process of decolourization of textile wastewaters. Two effluents were treated, and those were raw wastewater and after biological treatment. The optimization of this process was carried out by applying the central composite design, with variation of main Fenton reaction parameters ( $\mathrm{pH}$, initial $\mathrm{H}_{2} \mathrm{O}_{2}$ concentration and $\mathrm{RM}-550$ dose). Based on the experimental results, an empirical relationship between the response and independent variables was obtained, expressed by a second-order polynomial equation, as well as by 3D surface plots. The following optimal reaction conditions were obtained for raw effluent: $\mathrm{pH}=3.26 ;\left[\mathrm{H}_{2} \mathrm{O}_{2}\right]=10 \mathrm{mM}$; $[\mathrm{RM}]=0.09 \mathrm{~g}$, while for effluent after biological treatment: $\mathrm{pH}=3$; $\left[\mathrm{H}_{2} \mathrm{O}_{2}\right]=4.28 \mathrm{mM}$; $[\mathrm{RM}]=0.1 \mathrm{~g}$. Under the given conditions, the efficiency of the Fenton process was 61.8 and $79.6 \%$, respectively, due to different effluent characteristics. Namely, it is assumed that the higher decolourization efficiency after biological treatment was achieved due to partial degradation of dye molecules. Because of this, lower rates of hydroxyl radical production was required and therefore lower hydrogen peroxide consumption.

\section{ACKNOWLEDGEMENTS}

This research was financed by the Ministry of Education, Science and Technological Development of Republic of Serbia (Project III43005).

\section{REFERENCES}

[1] Babuponnusami, A. \& Muthukumar, K.: "A review on Fenton and improvements to the Fenton process for wastewater treatment", Journal of Environmental Chemical Engeneering, 2(1), 557-572, 2014. doi: 10.1016/j.jece.2013.10.011

[2] Benatti, C.T. \& Tavares, C.R.G.: "Fenton's Process for the Treatment of Mixed Waste Chemicals", In book: Organic Pollutants Ten Years After the Stockholm Convention - Environmental and Analytical Update, 247-266, 2012. doi: 10.5772/31225

[3] Bezerra, M.A., Santelli, R.E., Oliveira, E.P., Villar, L.S., Escaleira, L.A.: "Response surface methodology (RSM) as a tool for optimization in analytical chemistry", Talanta 76, 965-977, 2008. doi: 10.1016/j.talanta.2008.05.019

[4] Davarnejad, R. \& Azizi, J.: "Alcoholic wastewater treatment using electro-Fenton technique modified by $\mathrm{Fe}_{2} \mathrm{O}_{3}$ nanoparticles", Journal of Environmental Chemical Engineering, 4(2), 2016. doi: 10.1016/j.jece.2016.04.009

[5] Gebrati, L., Achaby, M.E., Chatoui, H., Laqbaqbi, M., Kharraz, J.E., Aziz, F.: "Inhibiting effect of textile wastewater on the activity of sludge from the biological treatment process of the activated sludge plant", Saudi Journal of Biological Sciences, 2018. doi: 10.1016/j.sjbs.2018.06.003

[6] Lodha, B. \& Chaudhari, S.: "Optimization of Fenton-biological treatment scheme for the treatment of aqueous dye solutions", Journal of Hazardous Materials, 148(1-2), 459-466, 2007. doi: 10.1016/j.jhazmat.2007.02.061

[7] Nidheesh, P.V.: "Heterogeneous Fenton catalysts for the abatement of organic pollutants from aqueous solution: a review", RSC Advances, 5(51), 2015. doi: 10.1039/C5RA02023A

[8] Soltani, R.D.C. \& Safari, M.: "Periodate-assisted pulsed sonocatalysis of real textile wastewater in the presence of MgO nanoparticles: Response surface methodological optimization", Ultrasonic Sonochemistry, 32, 181-190, 2016. doi: 10.1016/j.ultsonch.2016.03.011

[9] Torrades, F. \& García-Montaño, J.: "Using central composite experimental design to optimize the degradation of real dye wastewater by Fenton and photo-Fenton reactions", Dyes and Pigments, 100(1), 184-189, 2014. doi: 10.1016/j.dyepig.2013.09.004 


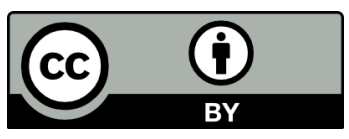

(C) 2018 Authors. Published by the University of Novi Sad, Faculty of Technical Sciences, Department of Graphic Engineering and Design. This article is an open access article distributed under the terms and conditions of the Creative Commons Attribution license 3.0 Serbia

(http://creativecommons.org/licenses/by/3.0/rs/). 